\title{
Dialogue, Knowledge Work and Tabletops: Lessons from Preservice Teacher Education
}

\author{
Andri Ioannou $^{1}$, Maria Zenios ${ }^{1}$, and Agni Stylianou ${ }^{2}$ \\ ${ }^{1}$ Cyprus University of Technology, Cyprus Interaction Lab, \\ Department of Multimedia and Graphic Arts, Limassol, Cyprus \\ ${ }^{2}$ University of Nicosia, Nicosia, Cyprus \\ andri.i.ioannou@cut.ac.cy, mkzenios@gmail.com, \\ stylianou.a@unic.ac.cy
}

\begin{abstract}
This pilot study is concerned with the exploration of tabletops in preservice teacher education, through the lens of sociocultural theories. An educational tabletop application designed to facilitate dialog and collaborative decision making, so called IdeasMapping, was enacted in the context of proposing a solution plan for a case study classroom problem. Students' responses to a questionnaire showed that they positively endorsed the technology for this type of collaborative activity. Moreover, analysis of video recordings of groups' discussions and interactions showed that the technology enhanced students' communication as they took turns in sharing their ideas, and provided structure and organization of these ideas linked to possible solutions on the problems embedded in the case.
\end{abstract}

Keywords: collaborative learning, collaborative decision making, surface computing, interactive tables, tabletops, preservice teacher education, case based learning, educational technology, technology integration.

\section{Introduction}

The emergence of technologies as part of our increasingly networked world has influenced higher education offering new exciting approaches to collaborative activities. Multitouch interactive tables (or tabletops) have been extensively discussed for their potential to support collaboration and learning. As discussed by [15], tabletops afford cooperative gestures which can enhance users' sense of teamwork, while the technology 'invites' interaction and willingness to participate in group work [17]. Despite its promise, integration and appropriate use of this technology in everyday school settings and in higher education classrooms is very limited.

As [14] recently argued there is "a problematic gap between what could be effective technology-enhanced learning (TEL) in theory, and what can be effective TEL in practice." In this pilot study, we view tabletops as a source of innovation in teacher education, that is also possible and practical today, in terms of supporting existing knowledge and practices within a shared physical space that allows the team to remain focused on the task at hand. We present an exploration of the use of tabletops in 
preservice teacher education within a classroom environment. The tabletop used in the study is equipped with IdeasMapping, an application that enables participants to develop a taxonomy of their ideas as they brainstorm (see section 1.3). Using the tabletop, groups of students discussed a case study classroom scenario and eventually created a taxonomy of ideas on how the teacher needs to respond to the problems embedded in the case.

\section{Theoretical Framing}

We explore the use of tabletops in pre-service teacher education through the lens of the Vygotskian sociocultural theory. The sociocultural perspective in education argues that human understanding and meaning is constructed through experiences and as part of a social context. It favors collaboration among peers while learning happens in situ, being located within tools and artifacts that play a pivotal role in the process. From a sociocultural perspective the use of tools plays an important role in extending human abilities and in enhancing thinking processes i.e., as in helping to create a representation of ideas or explicate one's thoughts. In this context, collaborative learning has been considered as key to knowledge creation in problem solving situations as it requires participation in shared activities, negotiation of ideas and decision making. As such, collaborative learning is essentially situated, contextual and discursive [20]. Further, collaborative learning has been claimed as one of the key skills that higher education institutions need to develop as, in today's society, problems which professionals need to tackle are often multi-faceted and need to be explored and targeted by multi-disciplinary groups. Researchers [7] have argued about the need of higher education to induct students into knowledge-building practices across different communities. Such practices often involve dialogical activities organised as part of learning environments potentially supported by technologies.

\section{Tabletops in Education}

In a recent review, [10] discussed the technological characteristics of interactive tabletops as well as their pedagogical affordances, drawing evidence from the education and computer science literature. Overall, as pointed out by the authors, most of what we know in this area concerns technical issues related to interaction of users with the technology, while we know little about the use and value of multitouch tabletops in formal and informal educational settings. Below we summarize some recent empirical evidence from the education arena.

Multitouch tabletops have been used with special user groups to promote development of social skills. SIDES, for example, is a four-player cooperative computer game designed to support adolescents with Asperger's syndrome practise social skills and effective group work during their group therapy sessions [16]. SIDES provided an engaging experience for this audience who remained engaged in the activity the entire time and learned from the activity (unlike typical behavior of this population). Similarly, StoryTable [5] has been used to facilitate collaboration and social interaction for 
children with autistic spectrum disorder with positive effects. StoryTable [2] was initially designed to support children's storytelling activity in groups; evaluation of StoryTable showed that it enforced cooperation between children during the storytelling activity, by allowing simultaneous work on different tasks, while encouraging them to perform crucial operations together in order to progress [2].

Furthermore, multitouch tabletops have been studied for their added benefits compared to singletouch tabletops in educational settings. Authors [8] contrasted groups of children in multitouch and singletouch conditions and found that children talked more about the task in the multitouch condition while, in the singletouch condition, they talked more about turn taking. A different study by [12] concerned the impact of particular tabletop interaction techniques on the type of talk during collaborative learning. The researchers found that different interaction techniques (direct touch, pantograph and non-digital table) resulted in different types of communication patterns during collaborative learning.

With regards to using tabletops in formal educational settings, a series of studies was conducted as part of the SynergyNet project [10] going beyond using single tabletops to studying a network of tabletops that can communicate with each other. SynergyNet undertook the development of curricula and tabletop applications for classroom integration focusing on how tabletops can best support collaboration in small groups. One SynergyNet study contrasted groups of children in multitouch and paper-based conditions to examine differences in their collaborative learning strategies [10]. The authors found that student groups in the multitouch condition maintained better joint attention on the task than groups in the paper-based condition. Another recent SynergyNet study examined NumberNet, a tool designed to promote within and between group collaboration in a mathematic classroom using a network of tabletops [9]; pilot results from 32 students showed significant knowledge gains from pre to post testing.

Last but not least, tabletops are considered engaging and fun. Researchers [1] assessed overall (perceived) usefulness and benefit of using tabletops in collaboration contexts with 80 participants. The study showed that groups in the tabletop experimental condition had improved subjective experience and increased motivation to engage in the task.

\section{$4 \quad$ Method}

IdeasMapping. This tabletop application is designed to support collaborative decision making by allowing the participants to analyze a problem and brainstorm around possible solutions, while they actively construct a consensus artifact, namely, a taxonomy of their ideas. The detailed functionality of the application, design methodology and user experience evaluation are reported elsewhere [19]. In IdeasMapping, collaboration is enforced in three stages:

Stage 1: With a problem at hand, each collaborator generates new ideas. Ideas are typed into a web application through the use of a mobile device such as a laptop or tablet (brainstorming stage). 
Stage 2: The ideas are presented one-by-one, as digital post-it notes on the tabletop surface and become subject to discussion amongst the collaborators. For each idea, collaborators make an effort to categorize it in a thematic unit; thematic units can be created by any participant (collaborative decision making stage).

Stage 3: Participants can finalize their taxonomy by editing ideas or generating new ones, deleting ideas or thematic units that are less promising, and relocating ideas into thematic units for a better fit until all collaborators are satisfied (consensus decision making stage).
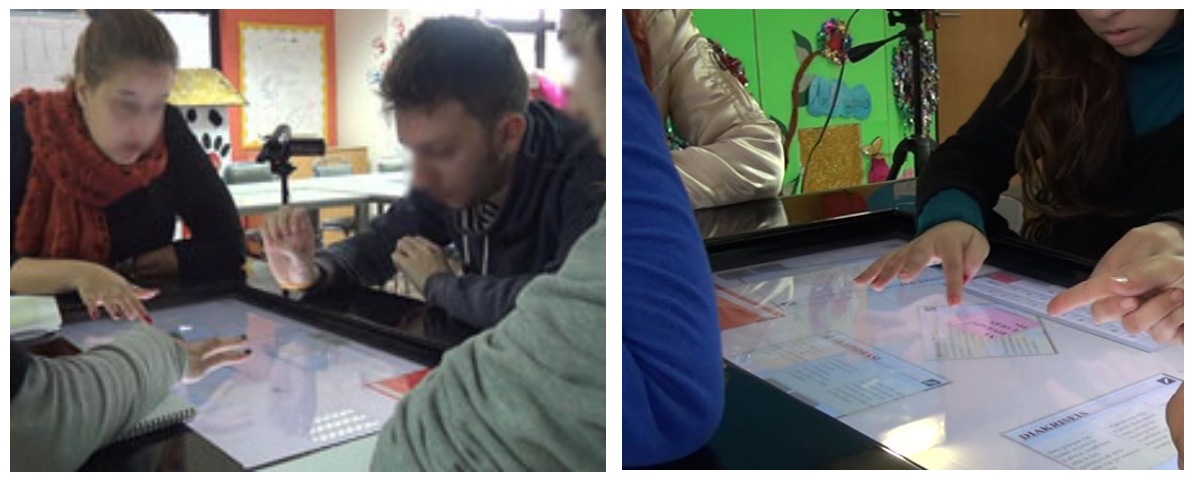

Fig. 1. Working in IdeasMapping

Participants. The participants were 20 undergraduate students, mainly females (80\%) between 20 and 22 years of age, in an Educational Psychology course, taught over 16 weeks at a private University in Cyprus. All of them were preservice teacher education candidates.

Procedures. Students were randomly assigned in five groups of four students each and were tasked to work collaboratively in their groups on a case study classroom scenario. They were to apply concepts learned in the course and argue for plausible solutions to the problem embedded in the case.

To ensure quality, the case scenario was adopted from a book specialized on the case study method by [6]. The scenario presented an ambiguous classroom problem concerning a 'divided' classroom where about $1 / 3$ of the students read below grade level (prefer worksheets), 1/3 read at grade level, and 1/3 read above grade level (prefer reading), leading to emotions of frustration and boredom for many students and making teaching very difficult.

Stage 1 of IdeasMapping (brainstorming stage) was carried out in distance. Students were given a week to read the case, think and record their ideas into the IdeasMapping web application. Then, Stages 2 and 3 involved collocated collaboration around the table. Each group met face-to-face and engaged in dialog and interaction around the table in an effort to categorize their different views and ideas into thematic units (see Fig. 1). Ultimately each group created consensus taxonomy of 4-5 main areas the educator needs work on to create a classroom environment for all students (see Fig. 1). 
Data Collection. A questionnaire was administered to all the participants at the completion of the activity. The questionnaire aimed to assess the perceived value of tabletop technology and IdeasMapping specifically for collocated collaboration on case study problems. Moreover, the sessions of all five groups were video recorded for subsequent video analysis.

\section{$5 \quad$ Analysis and Results}

Questionnaire Data. The questionnaire included 6 Likert-type items, with a 7-point agreement response scale (from 1: completely disagree to 7: completely agree), measuring the extent to which students thought the technology supported their collaboration. As shown in Table 1, means were well above the midpoint for all items, suggesting that the technology was positively endorsed by the participants.

Table 1. Descriptive statistics $(\mathrm{N}=20)$

\begin{tabular}{lll}
\hline \multicolumn{2}{l}{ Questionnaire Item } & Mead (SD) \\
\hline 1. & The tabletop met my needs as a collaborator. & $6.00(.89)$ \\
2. The tabletop allowed me to work effective in my team. & $5.81(.66)$ \\
3. The tabletop reinforced my participation in the activity. & $6.40(.63)$ \\
4. The tabletop helped promote collaboration between group mem- & $6.19(.54)$ \\
$\quad \begin{array}{l}\text { bers. } \\
\text { 5. }\end{array}$ & $6.25(.93)$ \\
$\quad \begin{array}{l}\text { learning. } \\
\text { 6. I would recommend tabletops to an educator aiming to promote } \\
\quad \text { collaborative learning. }\end{array}$ & $6.38(.89)$ \\
\hline
\end{tabular}

The questionnaire also included two open-ended questions concerning the pros and cons of using a tabletop for this type of collaborative activity. Using open coding [18] we found a couple of themes (codes) in students' responses, as described below:

The tabletop enabled physical communication, joined attention and awareness. Students pointed out how the physical shared workspace promoted collaboration by enabling physical communication, shared awareness, and shared attention on the group artifact. Some indicative student quotes on this idea include:

Group 1 participant: "Sitting together at one place and discussing and working together on the same artifacts kept our attention focused."

Group 2 participant: "I think the power of this technology is the shared digital display. Everyone can see and interact with artifacts on the tabletop and there is full awareness of everyone's actions."

Group 3 participant: "I felt the tabletop forced collaboration by bringing the teammates first physically closers and subsequently mentally closer. It was not too large like a typical round 
table, around which people get distracted. It was small enough to get us physically close and large enough to get us working together and thus, mentally close."

Shared power. Students also pointed out how the tabletop allowed 'power' to be shared and distributed over the display, thus enabling participation by all collaborators, for example:

Group 2 participant: "I liked how each of us could delete and add ideas. With the multitouch capability all participated and everyone's voice was heard."

Group 4 participant: "If we were to do this activity around a regular table I can see one student taking the lead and doing all the writing and making the decisions. I can see maybe another one somewhat contributing and the other two students looking outside the window! The tabletop discouraged one member from taking over, but encouraged everyone to contribute instead."

Last but not least, as one would expect with the integration of any new technology in the classroom, a novelty effect was also evident in students' responses. Several students commented how the tabletop was different, original, interesting and enjoyable among others. Of course, we consider this aspect less interesting, as technology should be intergraded to improve the nature of collaboration and learning, not because of its novelty.

Video Data. Analysis of video recordings of groups' discussions and interactions showed that the technology enhanced students' communication as they took turns in sharing their ideas, and provided structure and organization of these ideas linked to possible solutions on the problems embedded in the case. Below, we provide three examples of episodes demonstrating how ideas and thematic units were discussed and evolved as part of the collaboration process.

\section{Group 2 video episode (IdeasMapping Stage 1):}

P1: "With this idea I refer to the need for discipline. The teacher continuously threatens the students that there will be a sanction, but this does not occur ever. And the problematic behavior goes on and on. At least 3 students need to be punished based on what I read in the case." (originator of the idea)

P3: "Yes there are 2 boys...they fight during the recesses and continue their fight in the classroom. With sanctions, the rest of the students will also get the message...that the teacher is serious about punishment."

P2: "Should we create a theme named 'controlling behaviors'? Indeed there is a problem with students' behavior. Remember when a poor reader did the reading? Others were laughing at him, and this was very inappropriate."

P3: "Maybe we use a more general description of this theme to include actions towards addressing all these kinds of problematic behaviors?"

P4: "Let's name it 'behavior modification'. The teacher has to work on 'changing' students' behavior for the best." 


\section{Group 1 episode (IdeasMapping Stage 1):}

P1: "I feel collaboration will be a plus in Karen's lessons. Students have diffident abilities. With mixed-ability groups the strong readers may have a positive influence on the poor readers." (originator of the idea)

P4: "Did you pay attention to the details? ...that poor readers (1/3 of the students) enjoy completing worksheets. And another $1 / 3$ are neutral about both reading and worksheets. Indeed, Karen has to somehow mix these abilities. Instead of doing reading vs. worksheets, she should give them a group task of different nature, on which good readers and good worksheet-workers could work together and support each other."

P2: "How should we name this category? It does not fit with our other categories, right? It has to do with a change in the instructional methods and learning environment.

P1: "More specifically it has to do with promoting collaboration or even promoting interaction".

P3/P4 (together): "Let's name it 'promoting interaction'. It is more inclusive and may include other ideas too."

\section{Group 3 video episode (IdeasMapping Stage 1):}

P3: "My idea involves promoting collaboration using mixed-ability groups. She could create teams of poor and strong readers and give them tasks that require them to work together." (originator of the idea)

P2: "I have a similar idea coming up [refers to a post-it note not appeared yet]. I suggest that she integrates social tools into her lesson to promote communication across students and make it more interactive and fun."

P4: "Could this be named 'new instructional methods'? Collaboration in terms of peerfeedback would also help, I am thinking. Can we add this thought?"

P1: "I think we can add it later on...in Stage 2 of the app."

P2: "Yes, let's do 'new instructional methods' and we can add more ideas in there as we keep thinking."

\section{Discussion and Conclusions}

Overall, the results of this pilot study indicate that multitouch interactive tabletops provide a revolutionary approach to collaborative learning in preservice teacher education as they can enable the development of a shared space and physical communication between group members. The tabletop allowed the participants to add and delete ideas, and to take turns on discussing and critiquing thoughts until they agreed on a final taxonomy.

In particular, the results from the questionnaire data analysis showed that users' experience was very positive. Students thought the technology supported their collaboration and there was added value into using a tabletop for this kind of collaborative activity. Consistent with prior work on tabletops, these results provide further evidence of the affordances of tabletop systems to support dialog and collaboration on a group artifact in the context of problem based activities by enabling physical communication, joined attention and awareness (see also [4],[10]) and by distributing 
'power' over the display (see also [4], [11], [13]). Further, results from the video analysis demonstrated how the interactive tabletop enabled multiple points of control, in contrast to laptops and computers where team members have to negotiate their participation and often wait for their turn in using the devices (see also [8]). To this extent it can facilitate co-located collaboration and co-ordination as well as sharing of external representations among members that help them explicate their thinking as new developing teachers.

Dimensions of collaborative learning include interactivity, synchronicity and negotiability [3]. Work supported through tabletops enables learners being aware of the interactions among them that seems to influence co-participants' cognitive processes. Also, it shows the effort of an individual to model the knowledge state of a coparticipant. Further, it helps participants engage in dialogue and reach consensus. This occurs by enabling participants to create arguments in order to support alternative viewpoints, justify positions, negotiate meaning and attempt to convince each other.

However, it should be noted that at times the process was challenging for the students as they encountered difficulties in engaging in these tasks on their own. The role of the tutor was valuable in stimulating the participants in creating the appropriate linkages between their ideas while they used the multitouch tabletop. Further research needs to identify examples and types of teaching activities that will support student teachers in their use of tabletops. The pedagogic uses of tabletops in classrooms need to show how these activities can be designed, implemented and supported within a classroom.

Acknowledgments. Partially supported by the Cyprus Research Promotion Foundation (DESMI 2009-2010) under the "Bilateral Cooperation" between Slovenia and Cyprus ( $\triangle \mathrm{IAKPATIKE} \Sigma / \mathrm{KY}-\Sigma \Lambda \mathrm{O} / 0411)$.

\section{References}

1. Buisine, S., Besacier, G., Aoussat, A., Vernier, F.: How do Interactive Tabletop Systems Influence Collaboration? Computers in Human Behavior 28, 49-59 (2012)

2. Cappelletti, A., Gelmini, G., Pianesi, F., Rossi, F.: Zancanaro.: Enforcing Cooperative Storytelling: First Studies. In: Proceedings of the 4th IEEE Intentional Conference in Advanced Learning Technologies, pp. 281-285 (2004)

3. Dillenbourg, P.: What Do You Mean by 'Collaborative Learning'? In: Dillenbourg, P. (ed.) Collaborative Learning, Cognitive and Computational Approaches, pp. 1-16. Elsevier Science, Amsterdam (1999)

4. Fleck, R., Rogers, Y., Yuill, N., Marshall, P., Carr, A., Rick, J., Bonnet, V.: Actions Speak Loudly with Words: Unpacking Collaboration Around the Table. In: Proceedings of ITS 2009, Banff, Alberta, Canada (2009)

5. Gal, E., Bauminger, N., Goren-Bar, D., Pianesi, F., Stock, O., Zancanaro, M., Weiss, P.: Enhancing Social Communication of Children with High-functioning Autism Through a Co-located Interface. AI \& Society 24, 75-84 (2009), doi:10.1007/s00146-009-0199-0

6. Greenwood, G.E., Fillmer, H.T., Parkay, F.W.: Educational Psychology Cases, 2nd edn. Merrill Prentice Hall, Upper Saddle River (2002) 
7. Goodyear, P., Zenios, M.: Discussion, Collaborative Knowledge Work and Epistemic Fluency. British Journal of Educational Studies 55(4), 351-368 (2007)

8. Harris, A., Rick, J., Bonnett, V., Yuill, N., Fleck, R., Marshall, P., et al.: Around the Table: Are Multipletouch Surfaces Better than Single-touch for Children's Collaborative Interactions? In: Proceedings of the 9th International Conference on Computer Supported Collaborative Learning, pp. 335-344. ISLS (2009)

9. Hatch, A., Higgins, S., Joyce-Gibbons, A., Mercier, E.: NumberNet: Using Multi-touch Technology to Support Within and Between Group Mathematics Learning. In: Proceedings of the 9th International Conference on Computer Supported Collaborative Learning, pp. 176-183. International Society of the Learning Sciences (2011)

10. Higgins, S.E., Mercier, E.M., Burd, E., Hatch, A.: Multi-touch Tables and the Relationship with Collaborative Classroom Pedagogies: A Synthetic Review. International Journal of Computer-Supported Collaborative Learning 6(4), 515-538 (2011), doi:10.1007/s11412-011-9131-y

11. Ioannou, A., Zaphiris, P., Loizides, F., Vasiliou, C.: Let's talk about Technology for Peace: A Systematic Assessment of Problem-based Group Collaboration Around an Interactive Tabletop. Interacting with Computers (2013)

12. Jamil, I., O'Hara, K., Perry, M., Karnik, A., Subramanian, S.: The Effects of Interaction Techniques on Talk Patterns in Collaborative Peer Learning around Interactive Tables. In: Proc. CHI 2011, pp. 3043-3052. ACM (2011)

13. Marshall, P., Hornecker, E., Morris, R., Sheep Dalton, N., Rogers, Y.: When the fingers do the talking: A study of group participation with varying constraints to a tabletop interface. In: 3rd IEEE International Workshop on Horizontal Interactive Human Computer Systems 2008, pp. 33-40 (2008)

14. McKenney, S.: Designing and Researching Technology-Enhanced Learning for the Zone of Proximal Implementation. Research in Learning Technology 21 (2013),

http: / / ww . researchinlearningtechnology . net/index . php/rlt/ article/view/17374 (retrieved February 2014)

15. Morris, M.R., Huang, A., Paepcke, A., Winograd, T.: Cooperative gestures: Multi-user Gestural Interactions for Co-located Groupware. In: Proc. CHI, pp. 1201-1210. ACM (2006)

16. Piper, A.M., O'Brien, E., Morris, M.R., Winograd, T.: SIDES: A Cooperative Tabletop Computer Game for Social Skills Development. In: Proceedings of the 6th International Conference on Computer Supported Cooperative Work, Alberta, Canada (2006)

17. Rogers, Y., Lindley, S.: Collaborating around vertical and horizontal displays: Which way is best? Interacting With Computers 16(6), 1133-1152 (2004)

18. Strauss, A., Corbin, J.: Basics of Qualitative Research: Grounded Theory Procedures and Techniques. Sage, London (1990)

19. Zaphiris, P., Ioannou, A., Loizides, F., Vasiliou, C.: User Experience in Using Surface Computing for Collaborative Decision Making. Interactive Technology and Smart Education (2013)

20. Zenios, M.: Epistemic Activities and Collaborative Learning: Towards an Analytical Model for Studying Knowledge Construction in Networked Learning Settings. Journal of Computer-Assisted Learning 27(3), 259-268 (2011) 